\title{
Pablo Palazuelo e Victoria Vesna. Arte e Ciência, Laboratório de Formas
}

\author{
Angela Maria Gonçalves Cardoso
}

\begin{abstract}
Resumo
A exposição retrospetiva PABLO PALAZUELO Proceso de Trabajo. MACB-5-12-06 a 18-2-07; e a conferência (In) Tangibles: Nanopercepció i Mon Quantic. Vitoria Vesna, David Peat, CCCB- 24-3- 07, criam uma perspetiva da relação Arte-Ciência-Tecnologia. Essa perspetiva é aqui apresentada nos argumentos evidenciados pela obra deste artista e desta nanocientista. A obra, na sua função figurativa emergente, flui entre dois tempos: o da vida de Palazuelo (Madrid, 1915-2007) e Vesna (Washington D.C.,1960). Estas figurações materializam-se através da pintura e escultura em Palazuelo e em instalações interativas, ambientes digitais virtuais, performances polisensoriais, em Vesna. Palazuelo, em 1976, falava deste plano de interceções do seguinte modo: "La ciencia penetra cada vez más profundamente en el misterio de la materia formada, y el arte puede hacerlo también por sus propios medios, buscando alli otras cosas que aún no han sido reveladas." Este "tête a tête", conquista um espaço introdutório para a criação de obras unidas numa temática: a Mandala. O trabalho de atelier do pintor Palazuelo (Madrid, 1915-2007) e a obra nanomandala realizada pelos monges tibetanos de Gaden Kangtsen - County Museum de L.A. e Picolab.UCLA. A transição entre imagens de grãos de areia que revelam ondas padrão aparecendo a uma escala nanométrica, é evidente na referência formal e concetual na obra de Palazuelo. Assim sendo, as formas na matéria emergem seja pela via de atelier ou pela via de laboratório.
\end{abstract}

Palavras-chave: Arte-Ciência, Laboratório, Linguagem Gráfica

\begin{abstract}
The retrospective exhibition PABLO PALAZUELO Proceso de Trabajo. MACB-5-12-06 a 18-2-07; and the conference (In) Tangibles: Nanopercepció i Mon Quantic. Vitoria Vesna, David Peat, CCCB24-3-07, create a perspective of the Art-Science-Technology relationship. This perspective is presented here in the arguments evidenced by the work of this artist and this nanocientist. The work, in its emergent figurative function, flows between two times: that of the life of Palazuelo (Madrid, 1915-2007) and Vesna (Washington D.C., 1960). These figurations materialize through the painting and sculpture in Palazuelo and in interactive installations, digital virtual environments, polysensorial performances, in Vesna. Palazuelo, in 1976, spoke of this plan of interceptions as follows: "La ciencia penetra cada vez más profundamente en el misterio de la materia formada, y el arte puede hacerlo también por sus propios medios, buscando allí otras cosas que aún no han sido reveladas. "This "tête a tête", conquers an introductory space for the creation of works united in a theme: Mandala. The studio work of the painter Palazuelo (Madrid, 1915-2007) and the nanomandala work by the Tibetan monks of Gaden Kangtsen - County Museum of L.A. and Picolab.UCLA. The transition between images of sand grains that reveal standard waves appearing on a nanoscale scale is evident in the formal and concetual reference in Palazuelo's work. Thus, the forms in matter emerge either by atelier or by laboratory.
\end{abstract}

Keywords: Art-Science, Laboratory, Graphic Language 


\section{PABLO PALAZUELO E VITORIA VESNA}

LABORATÓRIO DE FORMAS

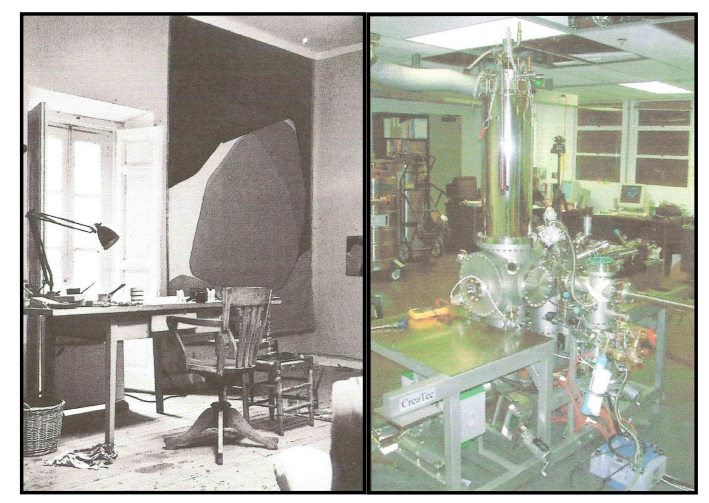

Fig.1 - Estúdio de Pablo Palazuelo. La Peralega. Galapagar. Madrid 1969

O conteúdo deste tema, evoluirá desde o acontecimento até a um argumento como contributo constitutivo da pergunta "como equacionar a relação arte, ciência, tecnologia?".

Consideramos ser definitivo no desenvolvimento deste estudo o facto de em 2007 termos tido a oportunidade de presenciar dois acontecimentos seguintes: A exposição retrospetiva PABLO PALAZUELO Proceso de Trabajo. MACB-5-12-06 a 18-2-07; e a conferência (In) Tangibles: Nanopercepció i Mon Quantic. Vitoria Vesna, David Peat, CCCB- 24-3-07.

Fascinados pelo conjunto de 350 obras de Pablo Palazuelo e igualmente atraídos pela visão alargada de Vitoria Vesna, aconteceu um fechar no tempo como investigadora, a que correspondeu uma abertura para uma outra perspetiva da relação arte-ciência- tecnologia dada por estas manifestações.

A relação arte-ciência ficaria intuitivamente gravada em nós como um espaço mental em que "sob a aparência do universo, do Tempo do Espaço e da Mobilidade está sempre encoberta uma realidade substancial, uma verdade fundamental em energia infinita. ${ }^{1 "}$

Essa realidade tentaremos retomá-la aqui nos argumentos evidenciados pelas obras destes dois artistas. A obra, na sua função figurativa ${ }^{2^{*}}$ emergente, flui entre dois tempos: 0 da vida de P. Palazuelo (Madrid, 1915-2007) e V.Vesna (Washington D.C.,1960).

Ambas manifestam entre si diferença e repetição, e o que pesa afinal nestes artistas é a sua liberdade, é a finalidade específica das suas vidas. Estas funções figurativas materializam-se através da pintura, escultura e escrita em Pablo Palazuelo; e em instalações interativas, ambientes digitais virtuais, performances polisensoriais, artigos académicos, por parte de Vitoria Vesna.

\footnotetext{
${ }^{1}$ Vesna, Victoria - in - http://nano.arts.ucla.edu

2 Zambrano, Maria. O Sonho Criador, 79

* "Função figurativa, modo propriamente criador que se dá em argumentos, nos quais a história declara o seu sentido e se salva em forma de poesia."
} 
P. Palazuelo, pintor, escultor, artista reflexivo, vivendo em Paris, no ano de 1952, na Rue St. Jaques (Notre-Dâme), rodeado de editores e livreiros especializados em literatura cabalística e esotérica, entrou na livraria La Tour de St. Jaques, atraído pelos livros expostos cheios de diagramas e signos. Aí conhece Claude d'Yge. Em relação a esse momento refere:

"Claude acabara de publicar una Anthologie de la Poesie Hermetique y Nouvelle Assemble des Philosophes Chymiques. (...) A partir de aquel encuentro se fue estableciendo una relación de amistad, más de maestro- discípulo que tuvo varias consecuencias para mí. Siguiendo su sindicaciones, comencé el estudio de algunos tratados de alquimia. Esos estudios, que exigen esfuerzo y paciencia los continúo aún hoy día. (...) De la lectura pasaba al trabajo gráfico (......"

$\mathrm{Na}$ sua vasta e profunda obra vinculada ao estudo do número, da física, do pensamento científico e pensamento oriental, a imaginação activa* funciona como catalisador dessa realidade oculta e o mundo real como um órgão de conhecimento.

Por outro lado, Vitoria Vesna, artista, catedrática do Dept. de Design/Media Arts.UCLA, diretora do Art/Sci Center e do VC Digital Arts Research Network, tem vinculada à sua obra e investigação a relação entre nanotecnologia, arte e cultura; V. Vesna afirma: "(...) procuro uma aproximação desde a perceção mais subtil no trabalho artístico tendo como finalidade os aspetos precetivos da física quântica. ${ }^{4 "}$

Paralelamente colocamos aqui as afirmações de Kevin Power acerca do aspeto percetivo na produção artística de P. Palazuelo:

'Palazuelo está embarcado en un 'relato' de lo que sabe, de lo que há percebido, sentido e visto como subyacente a todo. Busca las formas que subyacen a todas las formas, las energias que hacen que toda la energia se mueva, los cúmulos que guían a los campos de fuerza. Su obra trata del os ritmos de la percepción, de las estructuras y los patrones geométricos que subyacen a toda manifestación de vida y que están en nosotros e en la naturaleza, de las intuiciones de la percepción desnuda* y el carácter revelador de la visión. ${ }^{5 "}$

\footnotetext{
3 Palazuelo, P., Processo de Trabajo, 284-285

* P. Palazuelo - 1995-2005. Museo Reina Sofia. "(...) en sus escritos Palazuelo alude constantemente a la 'imaginación activa' e insiste en que es la energia que genera su obra. Corbin se expande sobre este significado en los siguientes términos: '(...) es el órgano que permite la transmutación de los estados espirituales internos en externos, en visiones que existen en una relación simbólica con dichos estados internos. Se alcanza el camino hacia el espacio espiritual, o es esta transmutación la que da un carácter espacial a este espacio, crea espacio, proximidad, distancia y lejanía (...) esta es la razón porque Palazuelo afirma que una vez que la abstracción se ha inventado ya no hay vuelta atrás."

${ }^{4} \mathrm{http}: / /$ sinapse.art.ucla.edu

* Gil, José, Imagem Nua e Pequenas Percepções, 18. A "Imagem Nua" caracterizada por no momento da sua percepção se encontrar despojada de significação real, pode encontrar-se em todo o domínio do real visível, em todas as representações de que os seus correspondentes verbais não se incluam,
} 
Este longo relato de que fala Kevin Power, o relato "de lo que há percebido, sentido e visto como subyacente a todo (... 6" é realizado no PICO LAB da UCLA (05) através de um instrumento, o SCANNING TUNNELING MICROSCOP (STM).

A magnificação na era da realidade virtual coloca a investigação no sentido de os cientistas conseguirem progressivamente alta definição da imagem a nível nanométrico. Uma equipa especializada da IBM encontrou um meio de manipular e mover átomos e moléculas, afirmando que não há limitações físicas.

O STM representa o paradigma em que o ver é substituído pelo tocar, sentir. Estão abertos novos campos criativos pela expansão de campos percetivos.

Poderemos dar como exemplo a obra INNERCELL (03) de Vitoria Vesna, que permite uma experiência espaciotemporal, em analogia com o nano-espaço. A manipulação atómica provoca uma alteração nos sentidos, complicando a normativa perceção do corpo e a compreensão da escala.

Por outro lado, SENCESPACES, Vitoria Vesna (03), pressentindo a saturação da imagem, cria a uma escala atómica a experiência de apreender através da subtileza do toque.

As palavras nanotecnologia, molécula, gene e virtual tornam-se os elementos chave desta experiência.

Perceber e sentir a nível do não-visível, são referências na obra de Palazuelo que afirma:

"(...) sujeto e objeto se interpenetran e se encuentran integrados en un todo que constituye un sistema vivo (...) la nueva visión de la realidad se funda en la toma de conciencia de que existe una interdependencia entre todos los fenómenos físicos, biológicos, psicológicos, sociales e culturales. (...) habría que formular una red de conceptos e modelos que pasarán por encima de las distribuciones convencionales entre disciplinas y utilizaran cualquier lenguaje siempre que este sea apropiado para describir los diferentes aspectos de la estructura de múltiples niveles. ${ }^{7 "}$

$\mathrm{O}$ argumento de alargamento de consciência percetiva, como meio e método para chegar à manifestação da representação, testemunhado múltiplas vezes nas afirmações de Pablo Palazuelo ao longo da sua vida, tem também na reflexão de Vitoria Vesna a preocupação de permitir a um grupo cada vez mais vasto de pessoas o conhecimento proporcionado pela instrumentalização da nanociência.

contendo uma carga não consciente de sentido. Verificamos então que estamos mergulhados num mundo de imagens nuas. A percepção de imagens nuas provoca um apelo de sentido."

5 Palazuelo, PabIo - Desdobrável da Exposição MACB.06-07

${ }^{6}$ Idem

7 Palazuelo, Pablo, Processo de Trabajo. E1 Paseante $n^{\circ} 4,1986$ 
V. Vesna afirma:

"Num curto período da história muitas coisas novas apareceram, criando as condições perfeitas para uma simbiose natural entre arte-ciência-tecnologia. Outra década passaria antes que as pessoas que ocupam estes mundos criativos expandissem o seu campo percetual relacionando os pontos de vista uns dos outros. Há uma necessidade genuína de abraçar novos sentidos, uma troca da perceção visual por outro tipo de perceções. A nanociência, a escala nanométrica, e a media art são poderosas sinergias que podem promulgar, no séc. XXI, a emergência de uma nova $3^{\mathrm{a}}$ cultura; abarcando trocas biologicamente inspiradas, uma nova estética e diferentes conceptualizações. ${ }^{8 "}$

Palazuelo, em 1976, falava deste plano de interceções da seguinte forma: "La ciencia penetra cada vez más profundamente en el misterio de la materia formada, y el arte puede hacerlo también por sus propios medios, buscando allí otras cosas que aún no han sido reveladas. ${ }^{9 "}$

Vitoria Vesna, em conferência na ARCO (Madrid-2006), falava sobre as tecnologias de comunicação afetam o comportamento coletivo, e como a perceção da identidade se relaciona com a inovação científica. 0 impacto da nanociência na consciência, de uma forma experiencial, leva-a a concluir o seguinte:

"Trata-se de compreender e manipular essa complexidade a níveis cada vez mais insuspeitados. Acredito que esta ciência precisa de outra forma de arte para interrelacionar, projetar e movimentar as pessoas numa nova forma de pensar para 0 mundo que vivemos. ${ }^{10 "}$

Este "tête a tête" que aqui colocamos entre estes dois artistas conquista um espaço introdutório para a referência de obras unidas numa mesma temática comum aos dois artistas, a temática da Mandala.

Mandala (do sânscrito manda-essência, la-contentor) tem como significado hindu o círculo concêntrico de energia.

Este símbolo encontra-se no Oriente e também nas Mandalas cristãs da Idade Média. Constitui um sistema de representação psico-cósmico, "onde a ação de criação de uma Mandala é devolvida a um domínio interior e sagrado que é forte e objetivo, contendo a unidade vida-consciência, revelador da Imanência e do seu potencial em nós mesmos, o retorno à unidade pela delimitação de um espaço sagrado e atualização de um tempo divino. ${ }^{11 "}$

\footnotetext{
8 Vesna, V., The Nanosindrome, http://sinapse.artsucla.edu

${ }^{9}$ Amon, Santiago, Conversación com Pablo Palazuelo, 10

10 Vesna, V, The Era of Posthuman Engineering - International Arts Experts Forum, ARCO 06

11 Power, K., La Imagínacion Activa. P. Palazuelo, 20
} 
A escolha das obras, a seguir indicadas, reflete não só a abordagem da mesma temática, mas também a relação arte, ciência e tecnologia na abertura que o cerne deste trabalho coloca: a diferença e repetição como fundamento para a sua análise conceptual e formal.

As obras em causa são: Pablo Palazuelo (1960-2007): MANDALA II - 1964 (1,46 x 88) Coleccion Sres René G. Zentner; MANDALA III - 1965 (2,35 x 1,44) - Coleccion Sres René G. Zentner; Vitoria Vesna: Monges Budistas Tibetanos. Mosteiro de Gaden Lhopa Kangtsen; SANDMANDALA 2006 - (8m x 8m). Los Angeles County Museum; NANOMANDALA - 2006 - (nano escala) - Instalação multimédia. Los Angeles County Museum. Pico Lab. VCLA.

A afirmação deleuziana que subtitula este capítulo, "todos os acontecimentos comunicam um único acontecimento ${ }^{12 "}$ enuncia a circunstância em que diferença e repetição, em cada obra, se mostra como algo que está aqui subjacente à ideia de infinitamente grande e infinitamente pequeno.

Citando Jorge Wagensberg argumenta-se que: "a procura é a (...) beleza: lo que se repite dentro de una misma cosa. (...) la inteligibilidad: lo que se repite en cosas diferentes. ${ }^{13 "}$

Neste caso os instrumentos da mente, o método da ciência, e os meios da técnica aproximamse para afirmar em diferença a ideia que leva até à visibilidade do apresentado.

12 Deleuze, Gilles, Diferença e Repetição, 57

13 Wagensberg, J., EI Gozo Intelectual, 149 


\section{PABLO PALAZUELO MANDALAS. MODUS OPERANDIS}

"No hablemos de quadros sino de ideas."

Abarcar o pensamento, o seu "corpo colossal de pensamento", e a obra deste artista não se justificaria neste contexto. Assim, para além da informação essencial ao entendimento da estrutura da sua mente íntima, processual, restringir-nos-emos à análise das obras MANDALA. Pablo Palazuelo atravessaria o portal da passagem do século num entorno de muitas outras circunstâncias artísticas, culturais, sociais e políticas.

A perspetiva de Kevin Power sobre a sua colocação na história da arte é a seguinte:

“(...) se diferencia de la abstracción clássica en que no busca la autonomia de las formas sino la tensión entre ellas, el proceso de transformación que ellas sufren. (...) de ahí que las investigaciones formales de Palazuelo constituyen una ruptura de los postulados modernistas, con la salvedad de que la literalidad en su obra es fruto de un proceso interior, reflexivo, a diferencia de la literalidad objectual del minimalismo."14

Esta transformação e o seu processo criador poderão enquadrar-se nos seguintes itens. Pablo Palazuelo refere que tudo se passa num espaço universal e mental, afirmando: "Mi visión del cosmos es atemporal. El universo es atemporal. El universo como un enorme pensamiento. ${ }^{15 "}$

Em relação ao carácter revelador da visão diz: "La visión es una forma de ver lo que no se ofrece a nuestra vista. Su papel en el fenómeno de la percepción es superior al que juegan los sentidos? "16" A imaginação ativa, conceito fundamental da função criadora, para Palazuelo tem um potencial visionário:

"El inconsciente pude producir, con grand efectividad y de modo espontáneo, la representación de una estructura matemática que sea expresión de una orden. (...) es la idea de epifanía, movida por fuerzas psico-espirituales la que domina a percepción. (...) una doctrina filosófica y científica que proporciona la traducción de una visión el mundo interior y exterior basado en ritmos o microcósmicos ${ }^{17 "}$.

Em relação a este assunto Kevin Power afirma:

"(...) El mundo imaginalis, mundo de la imagen, sería entonces un mundo tan real que desde el punto de vista ontológico como el mundo de los sentidos y del intelecto, un mundo que requiere una facultad de percepción que le pertenezca, una facultad cognitiva (...). . $^{1 "}$

\footnotetext{
${ }^{14}$ Power, Kevin, La Imagínación Activa, In Pablo Palazuelo, Processo de Trabajo, 11

${ }^{15}$ Power, Kevin, Geometria y Visión. Una Conversación con Pablo Palazuelo, 27

${ }^{16}$ Power, Kevin, Espiritualidade Orgânica de Palazuelo, 15

17 Idem

${ }^{18}$ Idem, 19
} 
Em relação à energia e à forma, tão importante na conceção a nível da manifestação pictórica, 0 artista afirma:

"Es la imaginación la que va añadiendo a las formas aquello que les falta para hacerse. Este seria el deseo verdadero, el deseo que no puede tener la ilusión de pararse en una forma definida y fija pues su objeto son las formas dela vida ilimitada. (...) la forma se manifiesta siempre con la energía e la materia. (...) las energías del universo contienen, como nos dice Jung, 'todas las condiciones y cualidades que determinan las formas'. Estas condiciones y cualidades son imperceptibles e irrepresentables hasta que no llegan al umbral de la conciencia donde adoptan las imágenes de estructuras numerales y geométricas. ${ }^{19 "}$

Falando da forma, Pablo Palazuelo acrescenta:

"La imaginación activa, se comporta como el hilo de pescar lanzado a las aguas oscuras, sin fondo, para captar un pez 'ictus', que a su vez es señal 'icnos', como escucha profunda que oye lo que de allí viene. (...). Las formas con las que trabajo tienen su propia historia genética, su historia familiar, pues siempre proceden unas de las otras y siempre son semejantes - en el sentido matemático - dentro de una determinada familia o linaje. ${ }^{20 "}$

Abordando a ideia da importância do desenho na sua obra, o artista tece a seguinte reflexão:

"Dibujar es tener una conciencia crepuscular, un estado ligeramente conciente. El acto de repetir, forma parte de esa conciencia crepuscular y sirve para provocar una transformación de la conciencia en una conciencia de duermevela. (...) Cuando dibujo se producen movimientos estructurales y otras alternancias en el despliegue de las sucesivas conformaciones que integran la composición, en todo momento pueden seguir moviéndose, según la coherencia interna de sus formas componentes. ${ }^{21 "}$

A afirmação do artista: "Si se mira bien, dibujar es cosa enigmatica $22^{*} "$ remete-nos para as primeiras obras sobre o tema Mandala no sentido da sua evolução estrutural.

\footnotetext{
19 Palazuelo, Pablo, Energia, Materia y Forma, in P. Palazuelo- Processo de Trabajo, 48

20 Palazuelo, Pablo, Energia, Materia y Forma, in P. Palazuelo- Processo de Trabajo, 53

${ }^{21}$ Esteban, Claude, Pablo Palazuelo, 20

${ }^{22}$ Idem, 32

* Mandala 'el ojo filosófico' o 'el espejo de la sabiduría'. Las formas laberínticas de Palazuelo de los anos sesenta pueden ser entendidas como Mandalas. El Mandala no es tan solo un medio sino que también reacciona sobre su creador. Cierto que Palazuelo no esta creando "Mandalas" en el sentido estricto del término, pero lo es que intenta crear 'imágenes' contemporâneas que sean capaces de situarse dentro de un dominio sagrado similar".
} 
Na correspondência entre Claude Esteban e Pablo Palazuelo, publicada pela galeria Maeght de Barcelona, há uma carta de Palazuelo que encerra com a seguinte pergunta: "Que és lo inmemorial, extraño que uno quiere conocer?"23

Esse imemorial, poderá ver-se em resquícios visíveis de desenhos na obra MANDALA (1958) (Fig. 5). A presença da linha na sua absoluta pureza de movimentos é, na obra de Palazuelo, indicador dessas formas que segundo o artista, são "signos y merices de todos los signos de todos los lenguajes, legibles e ilegibles (...)."24

O conceito de transgeometria abordado pelo artista, (na partícula trans - trânsito, passagem interior de um para o outro e matra - medida, matéria), usado como distinção entre a geometria de Palazuelo e a praticada pela maioria dos pintores, é assim descrito:

"(...) yo buscaba otra expresión diferente a la mera combinación de un triángulo y un rectángulo. Un lenguaje que goza de un aceso al entendimiento de las formas, de todas las cosas, ya que la materia-prima, cuyo símbolo es el agua, la fluidez y la fertilidad, el estado continuo de cambio. ${ }^{25 "}$

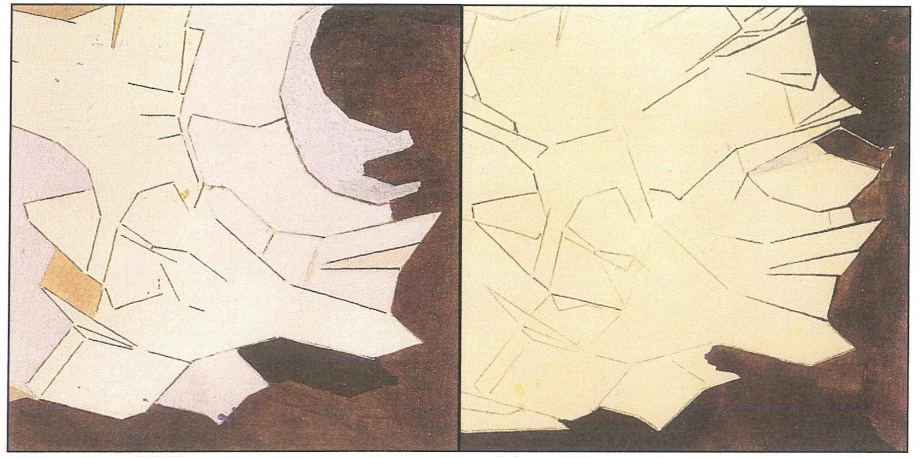

O conjunto de Mandala é claramente um exemplo desse trânsito da forma em que 0 artista mede forças com a íntima proporção da natureza na sua natureza. As "manifestações" apresentadas nas (Figs. 3,4), estão geradas a partir de linhas retas que se cruzam, linhas essas que, no entender de Villel Borja e José Cuyás, " (...) van del infinito al infinito. No son composiciones cerradas, sino abiertas, en expansión rítmica. $26 "$
Fig. 3 - MANDALA (39,5 x 25cm) Frente. 1956 Fig.4 - MANDALA $(39,5 \times 25 \mathrm{~cm})$ Verso 1956

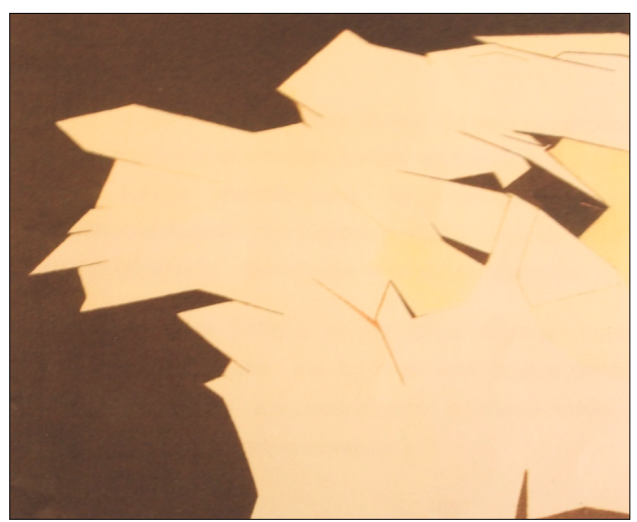

Fig.5 - MANDALA,1958. Carnegie Institute. Pittsburg

\footnotetext{
23 Palazuelo, P \& Esteban, Claudic- Palazuelo, 49

${ }^{24}$ Idem, 108

25 Power, Kevin, Espiritualidad Orgânica de Palazuelo, 21

${ }^{26}$ Cuyas, José \& Villell-Borja, Diálogos de los Números in Palazuelo, Proceso de Trabajo, 38
} 
A Mandala de 1958 (Fig. 5) é de suma importância para a repercussão Internacional da obra de Paulo Palazuelo. No ano em que faz uma exposição individual na galeria Maeght de Paris, consumaria nos Estados Unidos o seu reconhecimento ao obter o prestigioso Prémio Carnegie.

Esta obra é nitidamente parte evolutiva das de 1956, sendo que o traçado da linearidade do desenho desaparece quase totalmente abrindo um espaço pictórico de matéria em pulsação de formas latentes. Este é o registo de ritmos Cristalográficos de uma matéria superficial ou, como diria o seu autor; "rumor imperceptible llegado de outra escala del mundo.27"; ou, como Claude Esteban escrevia numa das suas cartas ao seu "Querido Palazuelo: "La musicalidad que se desprende de la composición e del encadenamiento de figuras, como un regreso al unísono, tras el concierto desordenado, caótico, de las voces singulares. ${ }^{28 "}$

O seu fundo é negro como ainda no seu consciente fundo, fundado sem forma e contendo todas as formas, fundo literal em devir. Este fundo manter-se-á na evolução destas obras temáticas, descultando no trabalho do artista as matérias e a sua energia fundadora, abrindo-se em cor reveladora.
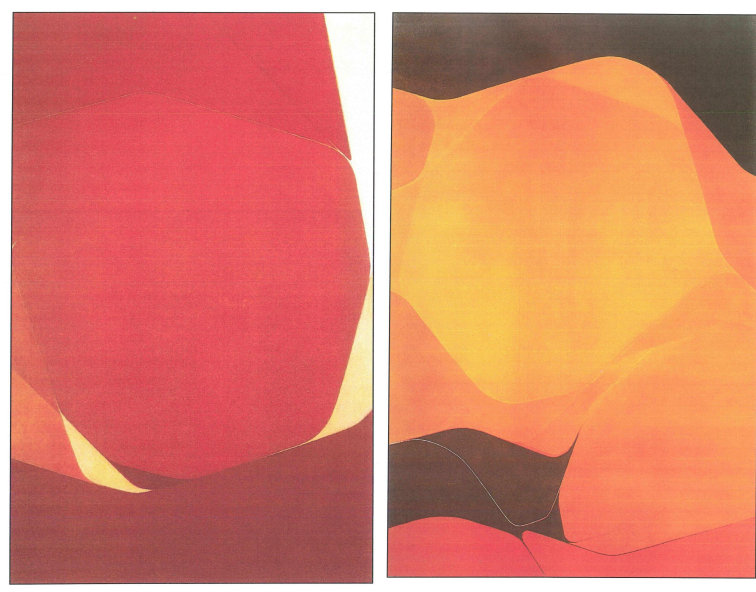

As investigações formais de Palazuelo sobre o ritmo falam-nos de relações entre a obra e a composição musical, referindo-se a elas nestes termos: "(...) lo que ellos llaman 'envolturas de sonido' inscritas en un polígono sugiere la onda. Se trata de una metamorfosis através de muchas operaciones gráficas. ${ }^{29 "}$

Fig.6 - Pablo Palazuelo, Mandala III, $(2,35 \times 1,44) 1965$.

Fig.7 - Pablo Palazuelo, Mandala II, (1,46x88cm) 1980.

Galeria Maeght - Barcelona.

Para além da manifestação de espaços ondulatórios provenientes da onda de energia dos polígonos, as obras apresentadas abarcam ainda outro elemento pictural, a cor. Não obstante a presença de branco, negro, vermelho e amarelo na sua obra, também aparece o verde e o azul. Resultado de um "processo informante", as Mandalas de 1964-65 (Figs. 3,4) são dominadas pelo vermelho, laranja, amarelo e ocre. Sobre a cor Palazuelo diz: "Me interesa la "trans-formación", o pasajes (...). El "rojo" estaria mas cerca del 'enrojecer' que de lo 'rojizo', y al mismo tiempo, violeta o naranja... y muy a menudo ennegrece o azulea. ${ }^{30 "}$

\footnotetext{
27 Esteban, Claude, Palazuelo, 117

${ }^{28}$ Idem, 125

29 Palazuelo, P., in Palazuelo. Amon, Santiago, 10

${ }^{30}$ Idem, 11
} 
Santiago Amon, em entrevista ao artista, pergunta: "Cabe estabelecer un particular simbolismo vital, desde el punto de vista estritamente cromático?31"

Em relação à operação alquímica e ao valor simbólico da cor, Pablo Palazuelo responde:

"En los procesos de sublimación de transformación de la sustancia, el alma humana 'imagina' la aparición de los colores en un orden que es casi constante. Pasa por el 'negro' (imaginado, primero como substancial-tenebroso), por el 'citrino iridiscente' (amarillo-verdoso, que evoca la multiplicidad de transformaciones), por el 'blanco' (la iluminación), y llega al ultimo 'rojo' que el artífice imagina rubió carbunclo por su orden cristalino y por ser 'receptáculo de la luz' (y del fuego). La aparición de una 'forma feliz' es siempre un acontecimiento maravilloso, (...) lo que colma los deseos del artista, que anuncia el 'fin' de sus trabajos. ${ }^{32 "}$

Cabe-nos acrescentar que esse "fin" como finalidade de encontro íntimo, na elaboração das Mandalas, inscreve-se no simbolismo da cor destas Mandalas, absolutamente realizado, correspondendo ao esquema de um princípio conciliador entre a "diversidade" da natureza e a "unidade" do espírito. Palazuelo continua afirmando ser necessário: "Levantar las infinitas arquiteturas de la vida. De la materialidad. El dios que canta es Orfeo. ${ }^{3{ }^{\prime \prime}}$

\section{VITORIA VESNA MANDALA. NANOMANDALA | MODUS OPERANDIS}

Cabe-nos agora dar início à apresentação e análise de uma obra que tendo como referência uma artista com formação de cientista, apresenta no seu trabalho semelhanças conceptuais com a obra de Pablo Palazuelo. Matéria e forma encontram realizações dissonantes que apesar disso se reúnem num único espaço de reflexão.

A relação arte-ciência é cabalmente assumida pelos dois, sendo seus referentes, por um lado, 0 tangível na ciência através da tecnologia, e na obra de Pablo Palazuelo o "tangível" na metafísica, através do experienciável na produção artística.

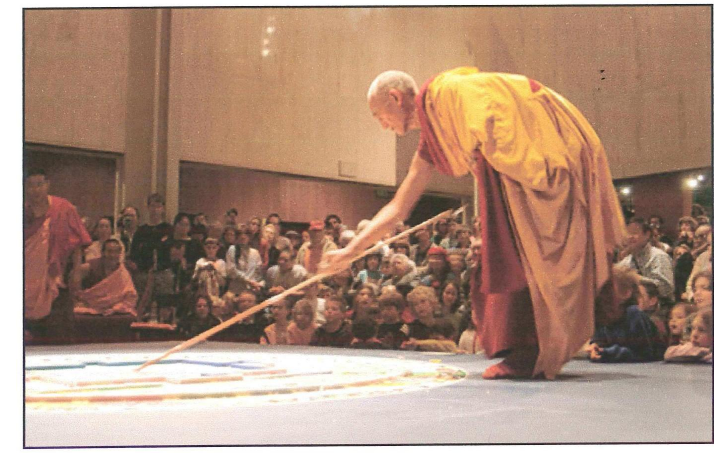

Fig.8 - Monges tibetanos, Gaden Kangtsen. Country Museum, L.A. 06

\footnotetext{
31 Ibidem, 11

32 Palazuelo, P., Palazuelo. Amon, Santiago, 12

${ }^{33}$ Idem, 10
} 
A Mandala de areia realizada pelos monges tibetanos do mosteiro Gaden Kangtsen, Índia, no Los Angeles County Museum (2006) em interação com a instalação multimédia NANOMANDALA de VICTORIA VESNA. ${ }^{34}$ (Los Angeles County Museum \& Pico lab.UCLA. 2006), é representativo do ideário desta artista-cientista.

A disposição intencional de átomos cria semelhanças com o método que os monges usam, para laboriosamente criarem imagens de areia, partícula a partícula; contudo as culturas ocidentais e orientais usam esta prática com diferentes perceções e propostas.

A instalação incorpora a Mandala (um diagrama cósmico e símbolo ritualista do universo, usado no hinduísmo e budismo, cuja tradução do sânscrito é de "todo", "círculo", "zero"), em conjugação com a exposição de Arte Budista no County Museum de L.A. A obra NANOMANDALA* foi conceptualizada da seguinte forma ${ }^{35}$ : Num suporte de oito metros de diâmetro coberto de areia branca, uma sequência de Mandala criada pelos monges tibetanos ao vivo e reproduzida num laboratório nanotecnológico (PICOLAB-UCLA), com um microscópio ótico de scanner por eletrões (SEM), são projetadas ambas as imagens.

Esta aproximação de arte, ciência e tecnologia é uma interpretação moderna de uma tradição que consagra o planeta e os seus habitantes para conseguir purificação e cura. Esta Mandala nunca tinha sido feita nos Estados Unidos. Depois de a Mandala de oito metros de diâmetro estar concluída, dois dos monges na companhia do nano cientista James Gimzewski36, recriaram o centro da Mandala diretamente sob o STU.

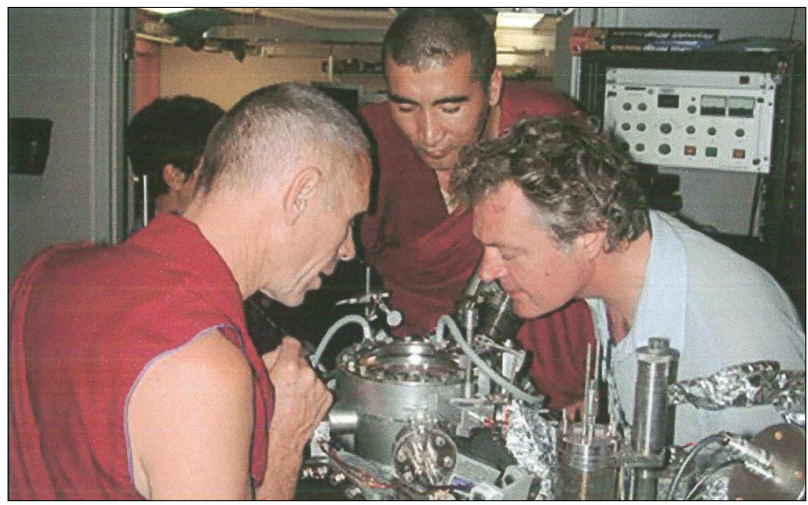

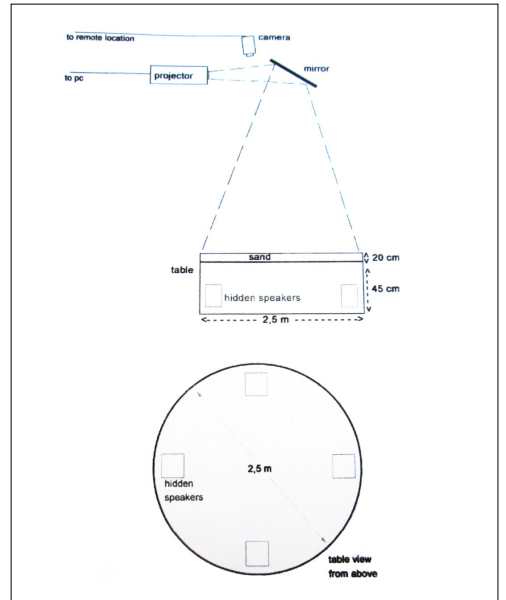

Fig.9 - Esquema Projectual e Técnico - NANOMANDALA

Fig.10 - Centro de Chahrasamvara, Monges tibetanos James Ginzewski.

\footnotetext{
34 Vesna, Victoria, http://nano.arts.ucla.edu

* Ucla - Design Media Arts

35 http://nano.arts.ucla.edu

36 http://lwwwdigicult.it/digimag/article.asp?id=668 - James Gimzewski (1956), Feynman Prize em nanotecnologia (97), Duddle Prize (01); membro honorário da Royal Academy de engenharia.
} 
Foi decidido pelos monges fazê-lo no espaço onde Vesna e Gimzewski fazem o seu trabalho de investigação (PICOLAB). O uso tecnológico de materiais muito mais delicados que a areia não intimidou os monges.

A criação da Nanomandala a nível microscópico começou com a transição do fim da magnificação obtida com a câmara digital para a do microscópio ótico. Amostras de areia que os monges usaram foram montadas no Microscópio Scanner de Electrões (SEM). Com alta definição; as imagens foram gravadas em resoluções que ultrapassavam as do microscópio ótico.

Criar a transição entre imagens de dois grãos de areia no SEM foi um desafio para a equipa. As imagens finais revelavam ondas padrão aparecendo a uma escala nanométrica. A ideia seria criar uma única imagem de Mandala até à nano escala; no entanto a tecnologia não estava preparada para lidar com um database de 300.000 imagens. A equipa decidiu por fim criar uma animação recorrendo a efeitos especiais.

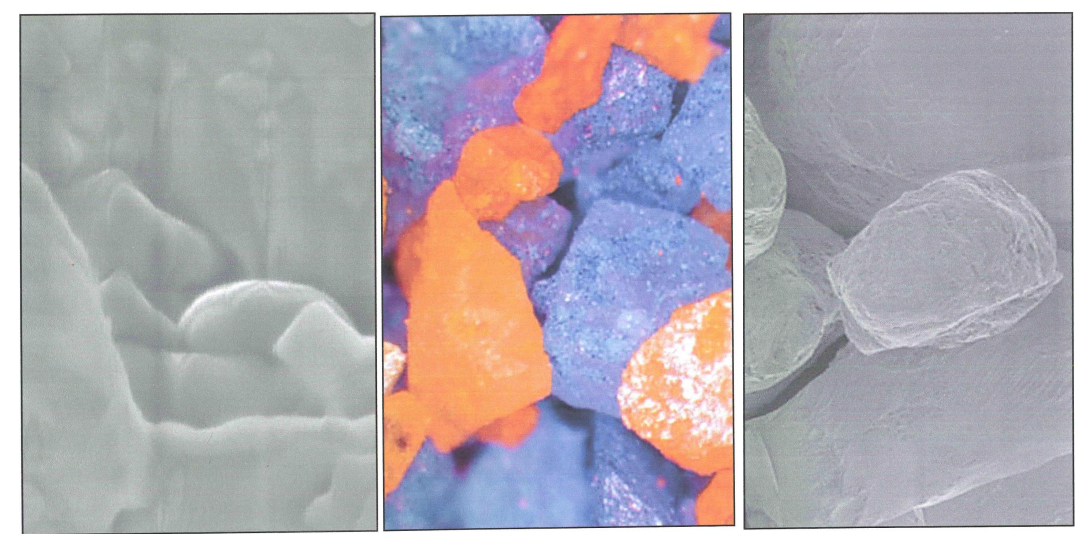

Fig.11 - ONDAS PADRAO a uma escala Nanométrica NANOMANDALA

Fig. 12 - Nanomandala. PICOLAB. UCLA. 06

Fig. 13 - Nanomandala. PICOLAB. UCLA. 06

Esta experiência de magnificação vivenciada como intermediária de expansão percetiva cria a seguinte reflexão em Vitoria Vesna:

"Vivemos numa cultura científica. Acontece em todo o lado e isto tem já um grande impacto no papel da arte. Artistas e humanistas tomam o papel de intérpretes e levantam questões sobre os pressupostos científicos. Eu abraço a tecnologia, mas como qualquer artista tomo liberdade para transgredir, redesenhá-la e questionar sobre o papel que ela tem na nossa vida. ${ }^{37 "}$

Estes territórios invisíveis confrontam-nos com múltiplos valores de escalas e articulam-se em diferentes níveis. Estamos perante uma viagem em novos campos de criação que nos mostram a

\footnotetext{
${ }^{37}$ Vesna, Victoria, http:///ucdametorg/projects/networkphp
} 
dinâmica do infinitamente pequeno, convidando-nos a procurar conhecer mundos paralelos e mentais de profunda carga imaginativa. Neste trabalho, Vitoria Vesna coloca o público literalmente dentro de um grão de areia; através da ciência que manipula a matéria até à escala do nanometer.

\section{REFLEXIVO: DIFERENÇA E REPETIÇÃO}
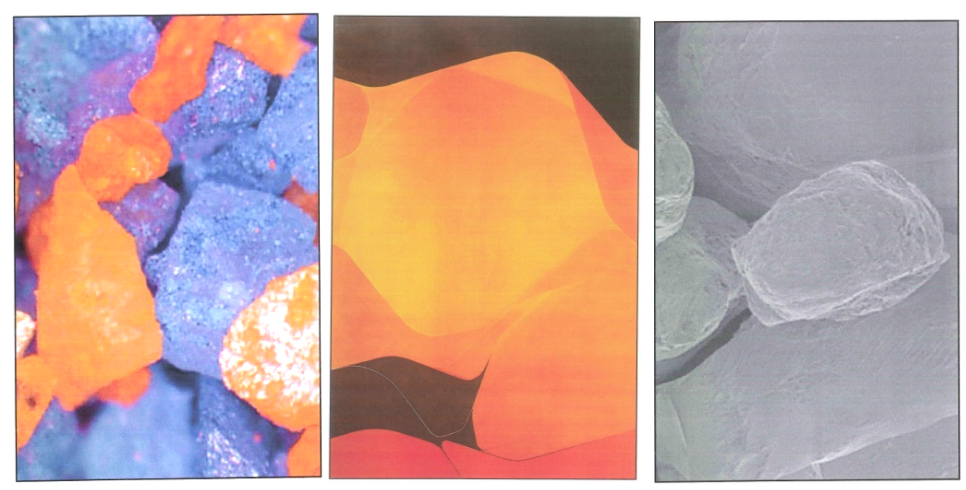

Figs. 14,15 - Pablo Palazuelo. Nanomndala. 2006

Fig. 16 - Pablo Palazuelo. Mandala Il. 1964

As imagens produzidas pelo PICOLAB-UCLA (2006) são indissociáveis das obras Mandala II e Mandala III (1964-65). Parece-nos pertinente, trazer a este aspeto da reflexão a análise da sua relação, (Figs. 14,15,16). Fazê-lo a nível conceptual e formal, pressupõe uma área de pensamento que permita manobrar a evidência desses corpus. Encontrámo-lo na obra do filósofo Gilles Deleuze, Diferença e Repetição, e na obra de Michel Foucault e Gilles Deleuze Theatrum Philosophicum.

Não podemos ter a pretensão de abarcar esse modo profundo de entrar no mundo, o do filósofo clarividente, como é o pensamento e o ideário de Gilles Deleuze. Esta é uma abordagem sintética, pois enunciamos neste estudo, apenas as ideias essenciais que nos pareceram relevantes na compreensão do fenómeno pelas semelhanças, diferença e repetição nas obras apresentadas.

Os termos dedutivos passam pela conceptualização das obras Mandala e Nanomandala. O seu pressuposto é comum. Podemos enunciar na procura de uma espiritualidade conduzida através de um ritual de representações simbólicas, em que os arquétipos relacionados com o micro e macrocosmos emergem no ato da "imagem no seu aparecer". À representação subjaz um denominador comum 
enunciado na seguinte afirmação de Deleuze: "Chamamos representação à relação do conceito com o seu objeto, sob este duplo aspeto, tal como se encontra efetuado na memória e na autoconsciência. ${ }^{38 "}$

Partilhando desta dedução, ambas as obras se vinculam a teorias formuladas a partir dos centros de consciência que, como no oráculo de Delfos que diz "conhece-te a ti mesmo", toma consciência de quem és, são um reflexo especular do universo mental. Essa mente, que em labor tecnológico se aproxima da infinitesimal matéria, é também a peculiar peça motriz de ambos os artistas.

Para além de todos os elementos mentais e processuais das três propostas: a do artista, místico e cabalista Pablo Palazuelo, a dos contempladores, os Monges Tibetanos do Mosteiro Gaden Khangsten e a da interativa, artista e Professora Universitária Vitcoria Vesna ficam sob o nosso olhar as provas que toda essa circunstância de reflexão sobre o tempo, o ser, a tecnologia e a obra; essas provas testemunhais são-nos dadas em pintura no atelier de Madrid de Palazuelo em 1956, em trabalho laborioso do ritual de pintura granular pelos monges tibetanos e em observação indiscreta da íntima matéria do mundo pela tecnologia do laboratório PICOLAB da Universidade da Calofórnia, Los Angeles.

Voltamos à ideia inicial de repetição, como potência de linguagem. A análise agora é formal. Situamo-la na ideia de fundo manifestada nestas representações como matriz fundadora. Sobre esta problemática Deleuze escreve: “(...) a liberdade não mediatizada do fundo, a descoberta de um fundo atrás de qualquer outro fundo, a relação do sem-fundo com o não-fundado, a reflexão imediata do informal e da forma superior, constitui o eterno retorno. ${ }^{39 "}$ Estando longe de percorrermos um pensamento circular: é necessário acrescentar que a repetição se opõe a todas as formas de generalidade.

O que também acontece aqui é que tentamos converter esta ideia de repetição num "novo", em relação com a diferença constitutiva das obras. Essa manifesta-se singularmente através da nanotecnologia, que nos permite dizer o que aqui aparece como exterior ao conceito, mas inerente a ele. Ou seja, a função, a mecânica instrumental, dependeu na sua conceptualização técnica do fim em vista. Seríamos levados a dizer que apenas existe repetição entre estas obras, encontramo-nos perante elementos da mesma identidade (os que estão vinculados à estrutura da matéria na forma) que atravessam 0 mesmo conceito e se revêm em diferentes médiuns. Repete-se o conceito, sem diferenciação entre as representações, pois são o mesmo na sua anterioridade. Deleuze: "Devemos

\footnotetext{
38 Foucault, M \& Deleuze, G., Theatrum Philoso Phicum, 72

39 Deleuze, Gilles, Diferença e Repetição, 137
} 
distinguir um sujeito secreto que se repete através deles, o verdadeiro sujeito da repetição.40" A questão da inovação tecnológica e científica e da sua influência na produção artística recoloca atualmente a questão dos limites da ciência através das UBIQUIDADES e MATERIALIZAÇÕES da arte.

Assim sendo, poderíamos inverter a questão dizendo: há influência da arte na inovação tecnológica e científica, sendo que as formas na matéria manifestam algo de essencial ao conhecimento da arte, seja por via do atelier ou por via do laboratório.

\section{Sobre a autora}

Angela Maria Gonçalves Cardoso

Universidade de Trás-os-Montes e Alto Douro

angelac@utad.pt

Artigo recebido em 12 de dezembro de 2019 Aceito para publicação em 06 de abril de 2020

${ }^{40}$ Foucault, M \& Deleuze, G., Theatrum PhilosiPhicum, 36 